\title{
Donor MHC and adhesion molecules in transplant arteriosclerosis
}

\author{
Chengwei Shi, ${ }^{1}$ Mark W. Feinberg, ${ }^{1}$ Dorothy Zhang, ${ }^{1}$ Anand Patel,,${ }^{1}$ Chang U. Sim, ${ }^{1}$ \\ Zhao Ming Dong, ${ }^{2,3}$ Susan M. Chapman, ${ }^{2}$ Jose-Carlos Gutierrez-Ramos, ${ }^{2,4}$ \\ Denisa D. Wagner, ${ }^{2,3}$ Nicholas E.S. Sibinga, ${ }^{1,5,6}$ and Edgar Haber ${ }^{1,5}$
}

${ }^{1}$ Cardiovascular Biology Laboratory, Harvard School of Public Health, Boston, Massachusetts 02115, USA

${ }^{2}$ Center for Blood Research, Boston, Massachusetts 02115, USA

${ }^{3}$ Department of Pathology,

${ }^{4}$ Department of Genetics, and

${ }^{5}$ Department of Medicine, Harvard Medical School, Boston, Massachusetts 02115, USA

${ }^{6}$ Cardiovascular Division, Brigham and Women's Hospital, Boston, Massachusetts 02115, USA

Address correspondence to: Nicholas E.S. Sibinga, Harvard School of Public Health, 677 Huntington Avenue, Boston, Massachusetts 02115, USA. Phone: (617) 432-3586; Fax: (617) 432-2980; E-mail: sibinga@cvlab.harvard.edu

Chengwei Shi's present address is: Novartis Pharmaceuticals, Summit, New Jersey 07901, USA.

Jose-Carlos Gutierrez-Ramos's present address is: Millennium Pharmaceuticals, Cambridge, Massachusetts 02139, USA.

Chengwei Shi and Mark W. Feinberg contributed equally to this work.

Edgar Haber is deceased.

Received for publication July 14, 1998, and accepted in revised form January 5, 1999.

Transplant-associated arteriosclerosis remains an obstacle to long-term graft survival. To determine the contribution to transplant arteriosclerosis of MHC and adhesion molecules from cells of the donor vasculature, we allografted carotid artery loops from six mutant mouse strains into immunocompetent $\mathrm{CBA} / \mathrm{CaJ}$ recipients. The donor mice were deficient in either MHC I molecules or MHC II molecules, both MHC I and MHC II molecules, the adhesion molecule P-selectin, intercellular adhesion molecule (ICAM)-1, or both P-selectin and ICAM-1. Donor arteries in which ICAM-1, MHC II, or both MHC I and MHC II were absent showed reductions in neointima formation of $52 \%, 33 \%$, and $38 \%$, respectively, due primarily to a reduction in smooth muscle cell (SMC) accumulation. In P-selectin-deficient donor arteries, neointima formation did not differ from that in controls. In donor arteries lacking both P-selectin and ICAM-1, the size of the neointima was similar to that in those lacking ICAM-1 alone. In contrast, neointima formation increased by $52 \%$ in MHC I-deficient donor arteries. The number of CD4-positive T cells increased by 2.8fold in MHC I-deficient arteries, and that of $\alpha$-actin-positive SMCs by twofold. These observations indicate that ICAM-1 and MHC II molecules expressed in the donor vessel wall may promote transplant-associated arteriosclerosis. MHC I molecules expressed in the donor may have a protective effect.

J. Clin. Invest. 103:469-474 (1999).

\section{Introduction}

Transplant-associated arteriosclerosis, characterized by diffuse and concentric intimal thickening in blood vessels of the transplanted organ, is the major cause of graft failure after the first year of transplantation (1-3). Although the pathogenesis of this disease remains unclear, clinical and laboratory studies both indicate that transplant arteriosclerosis is a local, immune-mediated process involving an interaction between the recipient's mononuclear cells and cells of the donor vessel wall (4-6).

Donor MHC molecules may foster transplant arteriosclerosis through immune-mediated injury to the donor vessel wall (7). These MHC I and MHC II antigens are recognized by host $\mathrm{CD}^{+}$cytolytic and $\mathrm{CD} 4^{+}$helper $\mathrm{T}$ cells, respectively, and can elicit specific immune responses (8). While increased expression of MHC I molecules in donor organs has been associated with acute rejection (9), increased expression of MHC II molecules has been linked to chronic rejection (10). Although it is clear that these molecules may become targets of the host's immune response, their functional significance in the development of transplant vasculopathy is not well understood.

Cell adhesion molecules are also important in transplant arteriosclerosis because they mediate recipient inflammatory cell attachment to and migration into the donor vessel wall (11). P-selectin, expressed on the surface of activated endothelial cells and platelets, is a glycosylated adhesion receptor for leukocytes (12). In P-selectin-deficient mice, leukocyte rolling and macrophage recruitment during an inflammatory response are reduced $(13,14)$. Another mediator of leukocyte migration, intercellular adhesion molecule (ICAM)-1, binds to lymphocyte function-associated antigen 1 and macrophage antigen complex 1 on leukocytes (11). In mice deficient in ICAM-1, allogeneic T-cell responses and leukocyte infiltration are reduced (15). In addition to their roles in leukocyte trafficking, adhesion molecules may also regulate the migration of smooth muscle cells (SMCs) within the vessel wall (16).

In previous studies of transplant arteriosclerosis, blocking antibodies have been used to investigate molecular mechanisms underlying neointima formation (17-19, for example). We recently developed a mouse model of 
carotid artery allotransplantation (20) and used it to identify immunologic components in recipient mice that are necessary for transplant arteriosclerosis $-\mathrm{CD}^{+} \mathrm{T}$ cells, B cells, and macrophages (21). We continue our analysis by using this model with donor arteries derived from knockout mice, an approach that avoids the potential problems of blocking antibody nonspecificity or cross-reactivity. In the present study we used donor carotid artery loops deficient in molecules that mediate antigen presentation (MHC I, MHC II, or both) or molecules that mediate leukocyte migration (P-selectin, ICAM-1, or both) to examine the donor's contribution to the development of transplant arteriosclerosis. Carotid artery loops were allografted from six mutant mouse strains into immunocompetent $\mathrm{CBA} / \mathrm{CaJ}$ recipients. The allografted loops were harvested 42 days after transplantation and their morphology, morphometry, and cellular composition were characterized.

Our findings indicate that both direct and indirect antigen presentation are necessary for the development of transplant arteriosclerosis and that the presence of MHC II and ICAM-1 in the donor vasculature is required for typical neointima formation. In contrast, P-selectin expression is not required for transplant arteriosclerosis. MHC I molecules from the donor vasculature appear to limit neointima formation and thereby may protect the function of the graft.

\section{Methods}

Animals. Table 1 lists the mutant mouse strains used as donors and their respective controls. $\mathrm{CBA} / \mathrm{CaJ}(\mathrm{H}-2 \mathrm{k})$ mice were used as recip- ients because a predictable and substantial neointima formed after transplantation of wild-type arteries from all donor strains. All mice were obtained from the Jackson Laboratories (Bar Harbor, Maine, USA) unless indicated otherwise in the table legend.

Transplantation. A donor carotid artery was attached in a loop onto the carotid artery of a histoincompatible recipient (20). The operation was performed on anesthetized mice under a dissecting microscope (Model M3Z; Wild, Heerbrugg, Switzerland). In the recipient mouse, a midline incision was made on the ventral side of the neck from the suprasternal notch to the chin. The left carotid artery was dissected from the bifurcation in the distal end toward the proximal end as far as was technically possible. The artery was then occluded with two microvascular clamps (8 $\mathrm{mm}$ long; Roboz Surgical Instruments, Rockville, Maryland, USA), one at each end, and two longitudinal arteriotomies $(0.5-0.6 \mathrm{~mm})$ were made with a fine needle (30 gauge) and scissors. In the donor mouse, both the left and right carotid arteries were dissected fully from the arch to the bifurcation. The graft was then transplanted paratopically into the recipient in an endto-side anastomosis with an $11 / 0$ continuous nylon suture under $16 \times$ or $25 \times$, and the skin incision was closed with a $4 / 0$ interrupted suture. The time from graft harvest to completion of anastomosis did not exceed $60 \mathrm{~min}$.

Histology and morphology. Grafts were harvested 42 days after transplantation, a point at which a fully developed, nearly occlusive lesion had been observed in carotid artery loops transplanted from wild-type controls to CBA/CaJ mouse recipients (20). The harvested loops were divided in two: one half (2-2.5 $\mathrm{mm}$ ) was fixed in methyl Carnoy's fixative and embedded in paraffin. The other half was fixed in $4 \%$ paraformaldehyde, embedded in OCT, and kept at $-80^{\circ} \mathrm{C}$. The homogeneity of lesion formation in this model was confirmed in our previous study (20) of consecutive serial sections from the center of the donor loop to the site of the anastomosis with the recipient
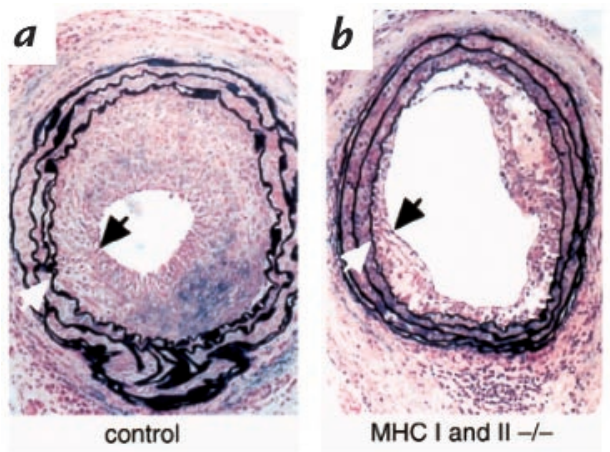

$\mathrm{MHC}$ I and II $-1-$

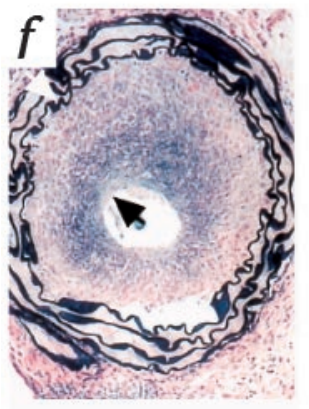

control

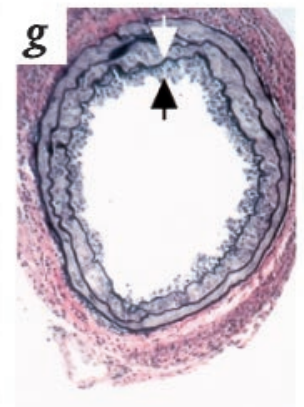

ICAM-1 -1-
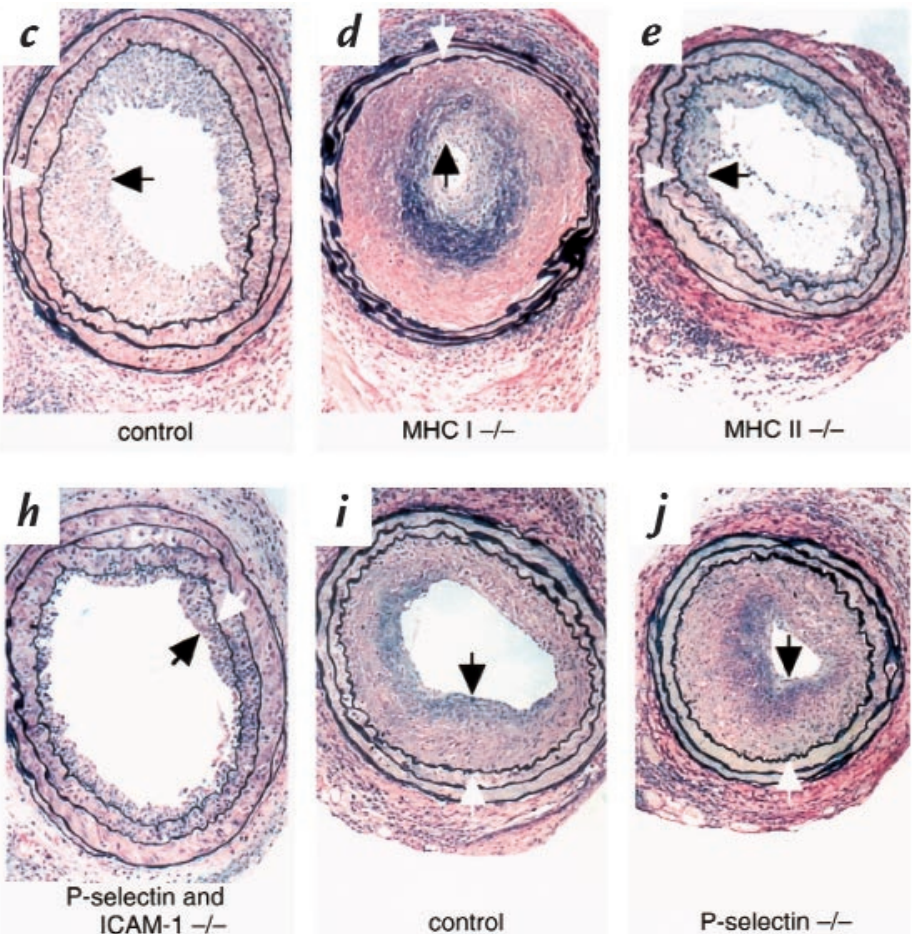

Figure 1

Sections of mouse carotid artery loops, 42 days after transplantation into histoincompatible recipients. Table 1 describes donor strains. CBA/CaJ mice were used as recipients. $(\boldsymbol{a}-\boldsymbol{j})$ Arrows mark neointima, which extends between the internal elastic lamina (Verhoeff's elastin tissue stain) and the vessel lumen. (a) B6129F2/J control for b. (c) C57BL/6J control for $d$ and $e$. (f) C57BL/6J control for $g$ and $h$. (i) 129 Sv control for $j$. $\times 150$. ICAM1 , intracellular adhesion molecule-1 
carotid artery. Sections for morphometry studies (5 $\mu \mathrm{m}$ thick) were obtained from the center of the graft to avoid the effects of the suture line. The areas of the neointima, the media, and the lumen were measured by computerized planimetry of sections obtained 150,300 , and $450 \mu \mathrm{m}$ from the center of the graft. Paraffin sections were stained with Verhoeff's elastin tissue stain anti- $\alpha$-actin antibody $(20 \mu \mathrm{g} / \mathrm{ml}$; Sigma, St. Louis, Missouri, USA), or anti-CD 45 antibody $(0.5 \mu \mathrm{g} / \mathrm{ml}$; PharMingen, San Diego, California, USA) (20). Frozen samples were stained with antibodies to CD4 $(10 \mu \mathrm{g} / \mathrm{ml})$ and CD $8(2.5 \mu \mathrm{g} / \mathrm{ml}$; both from PharMingen) (20). Morphometric and immunohistochemical analyses were performed as described (20).

Color video images were recorded from a Nikon Labophot-2 light microscope equipped with a Sony DXC-760MD video camera and control unit. Image analysis routines were created within a modified version (Organize-It Software, Boston, Massachusetts, USA) of the NIH Image 1.1 program. After tracing the area to be measured with the cursor, the operator sampled five pixels of the color that defined a given stain. The area encompassed by pixels (not always contiguous) in the color range for that stain was then computed automatically by the software. The neointima was defined as the area bounded by the internal elastic lamina and the lumen. The media was defined as the region between the internal and external elastic laminae. The lumen was defined as the clear part of the vessel in the center of the section.

\section{Results}

Intimal area in allografted arterial loops. Carotid arteries from six mutant mouse strains and their respective controls were allografted into immunocompetent $\mathrm{CBA} / \mathrm{CaJ}$ recipients (Table 1). In each arterial loop, the area of neointima formed 42 days after transplantation, on cross-section from the vessel lumen to the internal elastic lamina, indicated the degree of transplant arteriosclerosis (Fig. 1, between arrows in $a-j$; and Fig. 2). In arteries from MHC I and MHC II double-knockout donors, neointima formation decreased significantly ( $38 \%$ reduction, $P=0.005)$ 42 days after allografting into immunocompetent recipients (Fig. 1, $b$ vs. $a$; and Fig. 2). To determine the relative contribution of MHC I and MHC II molecules to this decrease in neointima formation, we also allografted

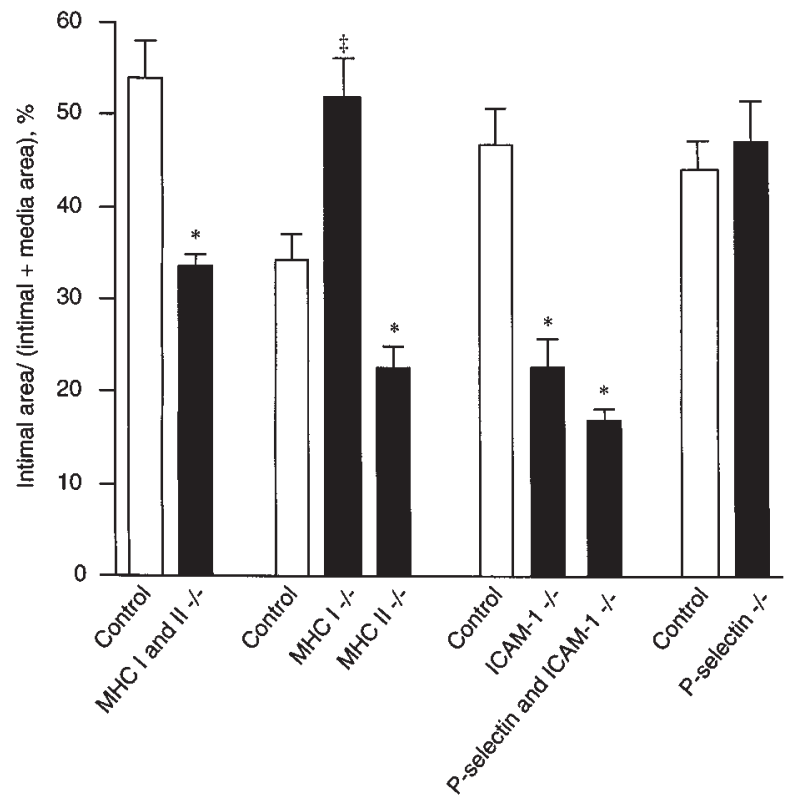

donor arteries from mice lacking either MHC I or MHC II. In arteries without MHC II molecules, a significantly smaller neointima formed ( $33 \%$ reduction, $P=0.02)$ than in arteries from wild-type donors (Fig. 1, e vs. c; and Fig. 2), indicating that the presence of MHC II was necessary for optimal neointima formation. To our surprise, a much larger neointima (52\% increase, $P=0.026)$ formed in donor arteries lacking MHC I molecules in comparison with arteries from wild-type donors (Fig. 1, $d$ vs. $c$; and Fig. 2), suggesting that the presence of MHC I in this setting may protect against transplant arteriosclerosis.

As with the MHC II-deficient donor arteries, the neointima that formed in donor ICAM-1-deficient arteries was markedly smaller $(52 \%$ reduction, $P<0.001)$ in comparison with wild-type donor arteries (Fig. 1, g vs. $f$; and Fig. 2). No further reduction in neointima formation occurred in donor arteries lacking both ICAM-1 and P-selectin (Fig. 1, $b$ vs. g; and Fig. 2). In donor arteries lacking only P-selectin, the robust neointima formation was not different from that in wild-type donor arteries (Fig. 1, j vs. $i$; and Fig. 2). This suggests that the reduction in neointima formation in donor arteries from P-selectin and ICAM-1 double-knockout mice was due mainly to the absence of ICAM-1 in the grafts.

Characteristics of the neointima in donor arteries. To determine whether the cellular composition of the reduced neointimas differed from that of the fully developed neointimas in controls, we stained transplanted arteries harvested 42 days after allografting for CD4, CD8, SMC $\alpha$-actin, and CD45. In wild-type donor arteries and in those deficient in MHC I and P-selectin, most of the neointima consisted of $\alpha$-actin-positive SMCs and, to a lesser extent, $\mathrm{CD} 45^{+}$inflammatory cells (Figs. 3 and 4). In contrast, in arteries from MHC II knockout donors, MHC I and MHC II double-knockout donors, and ICAM-1 knockout donors, the number of SMCs in the neointima was significantly lower than in arteries from wild-type donors (Fig. 4). In these arteries, CD $45^{+}$inflammatory cells were the major constituent of the reduced neointima

\section{Figure 2}

Intimal area in sections of mouse carotid artery loops, 42 days after transplantation into histoincompatible recipients. Table 1 describes donor strains. CBA/CaJ mice were used as recipients. B6129F2/J control donor, $n=6$; $\mathrm{MHCl}^{-/-}$and $\mathrm{MHC} \mathrm{II-/-}$ donor, $n=5 ; \mathrm{C} 57 \mathrm{BL} / 6 \mathrm{~J}$ control donor, $n=6$; $\mathrm{MHCl}^{-/-}$donor, $n=9 ; \mathrm{MHC} \mathrm{I}^{-/-}$donor, $n=8 ; \mathrm{C} 57 \mathrm{BL} / 6 \mathrm{~J}$ control donor, $n=9$; ICAM-1/- donor, $n=5$; P-selectin and ICAM-1/- donor, $n=8 ; 129$ Sv control donor, $n=7$; P-selectin ${ }^{-/-}$donor, $n=7$. Data (mean \pm SE) were subjected to ANOVA. Asterisks mark values significantly lower than respective controls: $\mathrm{MHC} \mathrm{I}^{-/-}$and $\mathrm{MHC} \mathrm{I}^{-/-}, P=0.005$; $\mathrm{MHC} \mathrm{I}^{-/}, P=0.021$; ICAM-1/- $P<0.001$; P-selectin and ICAM-1 ${ }^{--}, P<0.001$. Dagger marks value significantly higher than respective control: $\mathrm{MHC}^{1-1}, P=0.026$. 


\section{Figure 3}

Neointimal inflammatory cells $\left(\mathrm{CD} 45^{+}\right)$per carotid artery section, 42 days after transplantation. Nuclei were counted in each of three sections from five to six mice. Data (mean $\pm \mathrm{SE}$ ) were subjected to ANOVA. Asterisks mark values significantly higher than respective controls: $\mathrm{MHC} \mathrm{H}^{-/-}$ and $\mathrm{MHC} \mathrm{II--,}, P=0.0028$; $\mathrm{MHC} \mathrm{II}^{-/-}, P=0.02$.

(Fig. 3). The percentage of neointimal $\mathrm{CD}^{+} \mathrm{T}$ cells in donor arteries from MHC I knockout mice was significantly higher than in arteries from wild-type donors (2.8fold increase, $P=0.005$; Fig. 5). In donor arteries lacking MHC II molecules, CD4 ${ }^{+} \mathrm{T}$ cells decreased by $66 \%$ in comparison with controls ( $P=0.005$; Fig. 5$)$. The percentage of neointimal $\mathrm{CD}^{+} \mathrm{T}$ cells did not differ between MHC I knockout donors and controls (data not shown).

Isografted arteries harvested 42 days after transplantation did not show significant neointima formation. Consistent with our previous findings (20), in approximately $10 \%$ of the isografts we saw at most a single layer of cells that stained for $\alpha$-actin, and this layer formed only along part of the vessel circumference. In contrast, donor arteries deficient in MHC II molecules contained a small neointima of several layers that stained mainly for $\mathrm{CD}^{4} 5^{+}$leukocytes. Thus, the differences we observed in MHC II-deficient donor arteries were not only quantitative but also qualitative.

\section{Discussion}

Transplant arteriosclerosis is characterized by an early stage of transendothelial inflammatory cell migration, followed by the formation of a neointima in which smooth muscle cells accumulate $(7,21)$. Adhesion molecules on cells of the donor endothelium play an important role in this inflammatory infiltration (22-24). The experiments described here indicate that the neointima-forming response in MHC II-deficient donor arteries is significantly diminished. Because a small neointima did form in these arteries (Figs. $1 e$ and 2), alternative antigen-presentation pathways, such as the indirect pathway through the recipient's MHC molecules, may also be involved in the arteriosclerotic process.

\section{Figure 4}

Neointimal smooth muscle cells ( $\alpha$-actin-positive) per carotid artery section, 42 days after transplantation. Neointimal area corresponding to $\alpha$-actin-positive staining was measured automatically with a modified version of the NIH Image 1.1 analysis program (see Methods) in each of three sections from five to six mice. Data (mean $\pm \mathrm{SE}$ ) were subjected to ANOVA. Asterisks mark values significantly lower than respective controls: $\mathrm{MHC} \mathrm{I}^{-/-}$and $\mathrm{MHC} \mathrm{II}^{-/}, P=0.0073$; $\mathrm{MHC} \mathrm{II-/-}^{-1} P=0.0048$; ICAM-1/-, $P$ $=0.0084 ;$ P-selectin and ICAM-1 ${ }^{-/}, P=0.0071$. Dagger marks value significantly higher than respective control: $\mathrm{MHC} \mathrm{I}^{-/-}, P=0.011$.

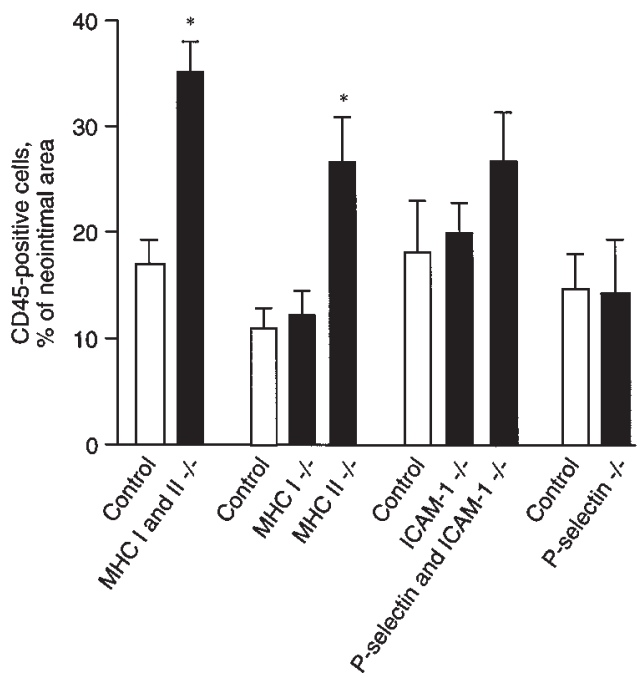

Nevertheless, we conclude that donor MHC II molecules play an important role in transplant arteriosclerosis, despite the small residual neointima in MHC II-deficient arteries. MHC I molecules present on graft vascular cells may protect against the formation of a neointima (Figs. $1 d$ and 2). In addition, ICAM-1 molecules, but not P-selectin molecules, must be present in the graft for robust neointima formation (Fig. 1, $g$ and $j$; and Fig. 2). Because this study was designed to examine the role in transplant arteriosclerosis of specific molecules expressed in donor tissues, the significance of MHC molecules, P-selectin, and ICAM-1 expressed by the recipient was not addressed.

$\mathrm{T}$ cells recognize allogeneic $\mathrm{MHC}$ molecules on a graft through the direct and indirect antigen-presentation pathways $(8,25)$. The direct pathway involves $\mathrm{T}$ cells that react against $\mathrm{MHC}$ molecule-peptide complexes expressed on the surface of donor (non-self) antigen-presenting cells (26). The indirect pathway involves T cells that recognize peptides derived from the processing and presentation of allogeneic MHC molecules by recipient (self) antigen-presenting cells (27). It has been proposed that the direct pathway may be involved primarily in acute rejection, whereas the indirect pathway may be more important in chronic rejection (8). In our study,

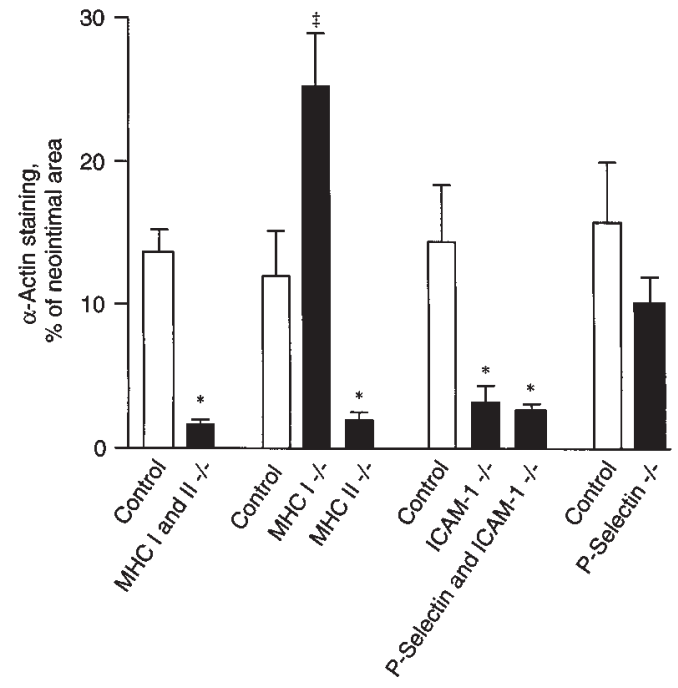


the smaller neointima formed in MHC II-deficient donor arteries (Figs. 1e and 2) indicates that the direct antigen presentation pathway is involved in the development of transplant arteriosclerosis. Since neointima formation was not totally abolished in these arteries, the indirect pathway may also be involved in the process.

Normal vascular endothelial cells do not express MHC II antigens, and SMCs express them at very low levels (6). In response to inflammatory stimuli, the vascular cells in grafts express MHC II antigens $(10,28)$. Moreover, in longterm mouse heart allografts stained with an allospecific antiserum, endothelial cells and SMCs have been shown to express MHC II molecules that derive from the donor (29). $\mathrm{CD}^{+} \mathrm{T}$ cells activated by MHC II-bearing graft endothelial cells can then infiltrate the graft and perpetuate the secretion of growth factors and cytokines. In MHC II-deficient donor arteries, the number of infiltrating $\mathrm{CD}^{+} \mathrm{T}$ cells decreased in comparison with that in arteries from wild-type donors $(P=0.005$; Fig. 5$)$. Thus, the absence of MHC II molecules on donor vascular cells may diminish the number of activated $\mathrm{CD}^{+}{ }^{+} \mathrm{T}$ cells and thereby reduce neointima formation. A deficit of $\mathrm{CD} 4^{+} \mathrm{T}$ cells would result in decreased cytokine secretion, leading to a decrease in macrophage activation and SMC proliferation, as proposed in our previous study (21).

Although the involvement of donor MHC I molecules in acute rejection has been examined $(7,9)$, their role in transplant vasculopathy is not well defined. In our study, donor arteries lacking MHC I molecules developed a larger neointima in comparison with controls (Figs. $1 d$ and 2), whereas medial cellularity did not change (data not shown). One possible explanation for the increase is that neointima formation may be mediated in part by an increase in $\mathrm{CD}^{+} \mathrm{T}$-cell infiltration $(P=0.005$; Fig. 5$)$. We have found previously that $\mathrm{CD} 4^{+} \mathrm{T}$ cells are important in transplant arteriosclerosis (21). MHC I molecules can negatively regulate natural killer (NK) cells (30). Cytokines secreted by NK cells are usually proinflammatory (31), contribute to the development of transplant arteriosclerosis $(10,32)$, and activate $\mathrm{CD}^{+} \mathrm{T}$ cells $(33)$. Thus, the lack of MHC I molecules in donor tissue may result in an increase in NK cell activity that may in turn stimulate the increased number of $\mathrm{CD}^{+}{ }^{+} \mathrm{T}$ cells and thus promote transplant arteriosclerosis. We cannot exclude the possibility in this model that recipient $\beta 2$-microglobulin could rescue donor tissue from a deficiency in MHC I expression, or that $\beta 2$-microglobulin deficiency in donor tissue could affect downstream or coregulatory molecules, such as the transporters associated with antigen processing (34). Although this form of rescue remains a theoretical possibility, Markmann et al. (35) have shown that expression of MHC I molecules in cultured $\beta 2$ microglobulin-deficient pancreatic islet cells is not reconstituted by the addition of $\beta 2$-microglobulin.

The development of transplant arteriosclerosis depends on an interaction between cells of the donor vessel wall and the host's mononuclear inflammatory cells (11). The endothelium provides the interface for this interaction (36). Endothelial cell activation/damage is a major factor in transplant arteriosclerosis (chronic rejection) (7). The

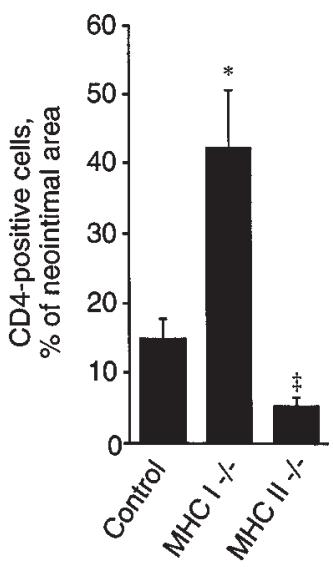

Figure 5

Neointimal CD4 ${ }^{+}$cells per carotid artery section, 42 days after transplantation. Nuclei were counted in each of three sections from five to six mice. Data (mean \pm $\mathrm{SE})$ were subjected to ANOVA. Asterisk marks value significantly higher than control: $\mathrm{MHCl}^{-/-}, P=0.005$. Dagger marks value significantly lower than control: $\mathrm{MHC} \mathrm{IH}^{-/-}, P=0.005$.

early stage in this process is dominated by subendothelial inflammatory cell infiltration (37). In response to inflammatory cytokines, endothelial cells increase their expression of proinflammatory surface adhesion molecules, which includes ICAM-1, P-selectin, and others $(9,38)$. Studies in vitro suggest that ICAM-1 may be more important in transendothelial leukocyte migration than other adhesion molecules (39), and studies in animals with antibodies to ICAM-1 show a decrease in cardiac allograft rejection $(17,18)$. Our experiments indicate that graftderived expression of ICAM-1 (one of several adhesion molecules involved in transendothelial migration) is critical to the development of transplant arteriosclerosis (Figs. $1 g$ and 2). Because ICAM-1 is also expressed on antigen-presenting cells such as macrophages, ICAM-1 can participate in the activation of $\mathrm{CD}^{+} \mathrm{T}$ lymphocytes after it has associated with MHC II-antigen complexes (40). Thus, the reduced neointima in ICAM-1-deficient donor arteries may have resulted from an interruption of the effect of ICAM-1 on leukocyte adhesion, transendothelial migration, or $\mathrm{CD}^{+} \mathrm{T}$-cell activation through association with MHC II molecules.

In contrast to ICAM-1, P-selectin does not contribute significantly to transplant arteriosclerosis in our model

\section{Table 1}

Mouse strains used as donors of carotid artery loops transplanted into $\mathrm{CBA} / \mathrm{CaJ}$ recipients

\begin{tabular}{|c|c|c|}
\hline Mutant & Defect & Control and haplotyp \\
\hline $\begin{array}{l}\mathrm{MHCl}^{-/-} \text {and } \mathrm{MHC} \mathrm{II}^{-/-} ; \mathrm{MHCl}^{-/} \\
\text {mice were mated with } \mathrm{MHC} \mathrm{II}^{-/-} \\
\text {mice }\end{array}$ & $\begin{array}{l}\mathrm{CD}^{+} \text {and } \mathrm{CD} 8^{+} \\
\text {T cells depleted }\end{array}$ & $\mathrm{B} 6129 \mathrm{~F} 2 / \mathrm{J}(H-2 b)$ \\
\hline $\begin{array}{l}\mathrm{MHCl}^{-/-} ; \beta 2 \text {-microglobulin } \\
\text { gene disrupted }\end{array}$ & $\mathrm{CD}^{+} \mathrm{T}$ cells depleted & C57BL/6J $(H-2 b)$ \\
\hline 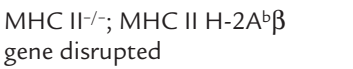 & $\mathrm{CD}^{+} \mathrm{T}$ cells depleted & $\mathrm{C} 57 \mathrm{BL} / 6 \mathrm{~J}(H-2 b)^{\mathrm{A}}$ \\
\hline $\begin{array}{l}\text { ICAM-1-/-; ICAM-1 gene } \\
\text { disrupted }\end{array}$ & ICAM-1 molecules deficient & $\mathrm{C} 57 \mathrm{BL} / 6 \mathrm{~J}(H-2 b)^{\mathrm{B}, \mathrm{C}}$ \\
\hline $\begin{array}{l}\text { P-selectin }{ }^{-/-} \text {and ICAM-1 } 1^{-/-} \\
\text {P-selectin } \\
\text { with ICAM-1- } \text { mice were mated } \\
\text { - } 1^{-/-} \text {mice }\end{array}$ & $\begin{array}{l}\text { P-selectin and ICAM-1 } \\
\text { molecules deficient }\end{array}$ & $\mathrm{C} 57 \mathrm{BL} / 6 \mathrm{~J}(H-2 b)^{\mathrm{B}, \mathrm{C}}$ \\
\hline $\begin{array}{l}\text { P-selectin-/-; P-selectin gene } \\
\text { disrupted }\end{array}$ & $\begin{array}{l}\text { P-selectin molecules } \\
\text { deficient }\end{array}$ & 129 Sv $(H-2 b)^{\mathrm{B}}$ \\
\hline
\end{tabular}

Mice were obtained from the Jackson Laboratories, except as noted. ${ }^{\mathrm{A} O b t a i n e d}$ from GenPharm. ${ }^{B}$ Provided by Denisa D. Wagner. ${ }^{C}$ Mice originally from a B6/129 mixed background were backcrossed six times to C57BL/6J. ICAM-1, intracellular adhesion molecule-1. 
(Figs. $1 j$ and 2). P-selectin is involved primarily in leukocyte rolling along the endothelium $(24,41)$. A comparison of P-selectin, low-density lipoprotein (LDL) receptor double-knockout mice with LDL receptor single-knockout mice suggested a role for P-selectin in early fatty streak formation (42). At later stages, however, there was no difference in fatty streak formation. We cannot exclude a role for P-selectin in transplant arteriosclerosis at very early stages, but our results with more advanced lesions suggest that P-selectin is not involved, or that its absence on donor tissues is well compensated by redundant adhesion mechanisms. Taken together, these observations suggest that P-selectin itself is not critical to the development of advanced vascular disease in different models of arteriosclerosis.

By examining this series of allografted carotid arteries, we have shown that donor MHC molecules and ICAM-1 molecules are important in transplant arteriosclerosis. In a recent clinical study, increased expression of MHC II molecules and ICAM- 1 in arterial tissue from transplanted hearts was found to be predictive of arteriosclerosis and graft failure (43). Our findings in this mouse model of transplant arteriosclerosis indicate that these molecules are not only markers but are also functionally important in the pathogenesis of the disease. Our results also suggest that donor MHC I molecules may play a protective role in transplant vasculopathy. Studies of grafts from genetically modified donors may further elucidate the specific molecular pathways of transplant arteriosclerosis and speed the identification of novel interventions.

\section{Acknowledgments}

We are grateful to Mu-En Lee and Mark A. Perrella for their critical review of the manuscript. We thank Lester Kobzik for reviewing the histological sections and Thomas McVarish for editing the manuscript. This work was supported by a grant from the Bristol-Myers Squibb Pharmaceutical Research Institute and by National Institutes of Health grants RO1 HL53756 (to D.D. Wagner) and HL-03274 (to N.E.S. Sibinga).

1. Sharples, L.D., et al. 1991. Risk factor analysis for the major hazards following heart transplantation-rejection, infection, and coronary occlusive disease. Transplantation. 52:244-252.

2. Billingham, M.E. 1989. Graft coronary disease: the lesions and the patients. Transplant. Proc. 21:3665-3666.

3. Sarris, G.E., et al. 1994. Cardiac transplantation: the Stanford experience in the cyclosporine era. J. Thorac. Cardiovasc. Surg. 108:240-252.

4. Billingham, M.E. 1995. Pathology of human cardiac transplantation. Monogr. Pathol. 37:108-128.

5. Hornick, P., et al. 1997. Influence of acute rejection episodes, HLA matching, and donor/recipient phenotype on the development of 'early' transplantassociated coronary artery disease. Circulation. 96:148-153.

6. Libby, P., Salomon, R.N., Payne, D.D., Schoen, F.J., and Pober, J.S. 1989. Functions of vascular wall cells related to development of transplantationassociated coronary arteriosclerosis. Transplant. Proc. 21:3677-3684.

7. Duquesnoy, R.J., and Demetris, A.J. 1995. Immunopathology of cardiac transplant rejection. Curr. Opin. Cardiol. 10:193-206.

8. Hornick, P., and Lechler, R. 1997. Direct and indirect pathways of alloantigen recognition: relevance to acute and chronic allograft rejection. Nephrol. Dialysis Transplant. 12:1806-1810.

9. Salom, R.N., Maguire, J.A., and Hancock, W.W. 1998. Endothelial activation and cytokine expression in human acute cardiac allograft rejection. Pathology. 30:24-29.

10. Libby, P., and Tanaka, H. 1994. The pathogenesis of coronary arteriosclerosis ("chronic rejection") in transplanted hearts. Clin. Transplant. 8:313-318.

11. Heemann, U.W., Tullius, S.G., Azuma, H., Kupiec-Weglinsky, J., and Tilney, N.L. 1994. Adhesion molecules and transplantation. Ann. Surg. 219:4-12.

12. Vestweber, D. 1992. Selectins: cell surface lectins which mediate the binding of leukocytes to endothelial cells. Semin. Cell Biol. 3:211-220.

13. Mayadas, T.N., Johnson, R.C., Rayburn, H., Hynes, R.O., and Wagner, D.D. 1993. Leukocyte rolling and extravasation are severely compromised in $\mathrm{P}$ selectin-deficient mice. Cell. 74:541-554

14. Johnson, R.C., et al. 1995. Blood cell dynamics in P-selectin-deficient mice. Blood. 86:1106-1114.

15. Xu, H., et al. 1994. Leukocytosis and resistance to septic shock in intercellular adhesion molecule 1-deficient mice. J. Exp. Med. 180:95-109.

16. Schwartz, S.M. 1997. Smooth muscle migration in vascular development and pathogenesis. Transplant Immunol. 5:255-260.

17. Isobe, M., Yagita, H., Okumura, K., and Ihara, A. 1992. Specific acceptance of cardiac allograft after treatment with antibodies to ICAM-1 and LFA-1. Science. 255:1125-1127.

18. Suzuki, J., et al. 1997. Inhibition of accelerated coronary atherosclerosis with short-term blockade of intercellular adhesion molecule- 1 and lymphocyte function-associated antigen- 1 in a heterotopic murine model of heart transplantation. J. Heart Lung Transplant. 16:1141-1148.

19. Murphy, B., Kim, K.S., Buelow, R., Sayegh, M.H., and Hancock, W.W. 1997. Synthetic MHC class I peptide prolongs cardiac survival and attenuates transplant arteriosclerosis in the Lewis Fischer 344 model of chronic allograft rejection. Transplantation. 64:14-19.

20. Shi, C., Russell, M.E., Bianchi, C., Newell, J.B., and Haber, E. 1994. Murine model of accelerated transplant arteriosclerosis. Circ. Res. 75:199-207.

21. Shi, C., et al. 1996. Immunologic basis of transplant-associated arteriosclerosis. Proc. Natl. Acad. Sci. USA. 93:4051-4056.

22. Allen, M.D., et al. 1992. Endothelial adhesion molecules in heart transplantation. J. Heart Lung Transplant. 11:8s-13s.

23. Jang, Y., Lincoff, A.M., Plow, E.F., and Topol, E.J. 1994. Cell adhesion molecules in coronary artery disease. J. Am. Coll. Cardiol. 24:1591-1601.

24. Ley, K. 1996. Molecular mechanisms of leukocyte recruitment in the inflammatory process. Cardiovasc. Res. 32:733-742.

25. Tullius, S.G., and Tilney, N.L. 1995. Both alloantigen-dependent and -independent factors influence chronic allograft rejection. Transplantation. 59:313-318

26. Liu, Z., et al. 1993. Contribution of direct and indirect recognition pathways to T cell alloreactivity. J. Exp. Med. 177:1643-1650.

27. Shoskes, D.A., and Wood, K.J. 1994. Indirect presentation of MHC antigens in transplantation. Immunol. Today. 15:32-38.

28. Steinhoff, G., Wonigeit, K., Schafers, H.J., and Haverich, A. 1989. Sequential analysis of monomorphic and polymorphic major histocompatibility complex antigen expression in human heart allograft biopsy specimens. J. Heart Transplant. 8:360-370

29. Hasegawa, S., Becker, G., Nagano, H., Libby, P., and Mitchell, R.N. 1998. Pattern of graft- and host-specific MHC class II expression in long-term murine cardiac allografts: origin of inflammatory and vascular wall cells. Am. J. Pathol. 153:69-79.

30. Timonen, T. 1997. Natural killer cells: endothelial interactions, migration, and target cell recognition. J. Leukocyte Biol. 62:693-701.

31. Robertson, M.J., and Ritz, J. 1990. Biology and clinical relevance of human natural killer cells. Blood. 76:2421-2438

32. Dong, C., et al. 1996. The pathogenesis of cardiac allograft vasculopathy. Curr. Opin. Cardiol. 11:183-190.

33. Janeway, C.A., Jr., and Travers, P. 1997. Immunobiology: the immune system in health and disease. Current Biology/Garland Publishing. London, United Kingdom/San Francisco, CA/New York, NY. 9:30-9:33.

34. Pamer, E., and Cresswell, P. 1998. Mechanisms of MHC class I-restricted antigen processing. Annu. Rev. Immunol. 16:323-358.

35. Markmann, J.F., et al. 1992. Indefinite survival of MHC class I-deficient murine pancreatic islet allografts. Transplantation. 54:1085-1089.

36. Fyfe, A.I. 1992. Transplant atherosclerosis: the clinical syndrome, pathogenesis and possible model of spontaneous atherosclerosis. Can. J. Cardiol. 8:509-519.

37. Cramer, D.V., et al. 1992. Lymphocytic subsets and histopathologic changes associated with the development of heart transplant arteriosclerosis. J. Heart Lung Transplant. 11:458-466.

38. Tanio, J.W., Basu, C.B., Albelda, S.M., and Eisen, H.J. 1994. Differential expression of the cell adhesion molecules ICAM-1, VCAM-1, and E-selectin in normal and posttransplantation myocardium. Cell adhesion molecule expression in human cardiac allografts. Circulation. 89:1760-1768.

39. Oppenheimer-Marks, N., Davis, L.S., Bogue, D.T., Ramberg, J., and Lipsky, P.E. 1991. Differential utilization of ICAM-1 and VCAM-1 during the adhesion and transendothelial migration of human T lymphocytes. J. Immunol. 147:2913-2921.

40. van de Stolpe, A., and van der Saag, P.T. 1996. Intercellular adhesion molecule-1.J. Mol. Med. 74:13-33.

41. Frenette, P.S., and Wagner, D.D. 1997. Insights into selectin function from knockout mice. Thromb. Haemostasis. 78:60-64.

42. Johnson, R.C., et al. 1997. Absence of P-selectin delays fatty streak formation in mice. J. Clin. Invest. 99:1037-1043.

43. Labarrere, C.A., Nelson, D.R., and Faulk, W.P. 1997. Endothelial activation and development of coronary artery disease in transplanted human hearts. JAMA. 278:1169-1175. 